\title{
Leadership style and Organizational Performance: A Comparative study between Transformational and Transactional Leadership styles
}

\author{
Hammad Tahir ${ }^{1}$ \\ Institute of Business \& Technology
}

\begin{abstract}
Purpose: This study has been conducted with objective to investigate the various leadership characteristics of Transformational and Transactional Leadership and then to empirically analyze the effect of each type of leadership on the organizational performance.

Methodology/Sampling: This study considers a sample of 800 respondents has been interviewed to collect the required information. The sample includes employees at tactical and operational management in corporate sector. Factor analysis which has been applied to determine the key characteristics of each type of leadership, thereafter the OLS estimation has been applied to test the hypotheses of the study.

Findings: The study concludes that the Charismatic Action, Intellectual Stimulation, Inspiration Motivation, Encouragement for High Morale characteristics of Transformational Leadership has significant positive effect on the Organizational Performance. In regard of the Transformational Leadership the further concludes that the Individual Consideration act of Transformational Leadership does not has significant effect on the Organizational Performance. A final conclusion based on the empirical analysis is that Transformational Leadership has significant positive effect on Organizational Performance, whereas, the Transactional Leadership has significant negative effect on the organizational Leadership. Practical Implications: This study provides empirical evidences that the Transformational Leadership is the most effective leadership in organizational performance. The key success factors or characteristics for a transformational leadership are Charismatic Action, Intellectual Stimulation, Inspiration Motivation, and Encouragement for High Morale characteristics of Transformational Leadership.
\end{abstract}

Keywords : Transformational Leadership, Transitional Leadership, Charismatic Action, Management by Action

\section{Jel Classification: M120, M540}

\footnotetext{
* The material presented by the author does not necessarily portray the viewpoint of the editors and the management of the Institute of Business \& Technology (IBT)

1. Hammad Tahir : : Hammad02@gmail.com
} 


\section{INTRODUCTION}

\subsection{Overview of the Study}

Effective Leadership, employee job satisfaction, and organizational commitment are the three important facets for organizational success. An effective leader provides guidance to employees, gives them direction towards achievement of desired goals, as a result employees with high job satisfaction exert more effort in completion of work for achieving success and thus are more committed towards organization (Voon, Lo, Ngui, \& Ayob, 2010). Many aspects of leadership style and organizational commitment have been studied in the earlier studies. Theorists define leadership as "a process of dealings between leaders and assistants where a leader tries to sway the behavior of his or her subordinates to achieve company goals" (Lo, Ramayah, Min, \& Songan, 2010).

Organizations face many challenges, but one of the greatest one is ensuring the wellbeing of its employees. Understanding of the association among job satisfaction, employee organizational commitment, organizational culture, and leadership is important because it assists in creating an efficient and motivated workforce and allows for an organization to achieve better overall goals \& objectives (Amburgey, 2005). As Bass and Avolio (1994) defines "Transactional leadership theory is a trade of rewards with subordinates for services provided. This seeks to motivate followers through extrinsic rewards". On the contrary.

\subsection{Background of the Study}

Many articles were taken of renowned scholars and researchers. Different views were generated in each of the research which instead leads to different results. The work of Marcoulides and Heck (1993) serves two areas; first, put forward the model relevant to how the culture of an organization influence the organizational performance. Second, make obvious the purpose of LISREL to reckon the model. It further explains the hypothesized culture comprising of three interconnected scope. The study also shows that the known features of culture can provide effective information which instead directs the organizations. It also defines the reason why the firms are not able to attain and sustain the required level of performance and productivity. 1.3 Theoretical Bases of the Study

\subsubsection{Leadership Styles}

The top management plays a very vital role in an organization, as these executives carry the organization in a very diplomatic way by which the role of employees is not much significant but they have to make employees feel to be a part of their organization. For this reason the employees encourage the style in which they have the authority. Like, employees don't support a leadership style in which they think that their idea is not being taken seriously, they need a decentralize system in which their suggestion and their decisions are given the same importance and this creates motivational factor amongst the employees which gives a positive outcomes (Wang \& Clegg, 2011). The leaders have influence on the behavior of their employees by their leadership style. The two leadership styles, transformational and consideration work which is people oriented have result to have a relationship with each other in a team work with respect to the leadership share in regards of the culture, age and gender it seems like to be most suitable leadership style having a positive relationship (Rowold, 2011). Leader-Member Exchange (LMX Theory) is about how people carry a leadership position in a group through different means and exchange important information which 
Leadership style and Organizational Performance: A Comparative study between Transformational and Transactional Leadership styles

create a strong relationship between the employees of the organization (Carolina Gomez \& Benson Rosen, 2011). Leader-member exchange is all about the relation between the leaders and their team, this theory have a very particle and theoretical application which is very useful but it has some problems which are like the measurement of its effectiveness and its application (Schyns \& Blanc, 2011).

\subsubsection{Empowerment}

The term empowerment is a very diversify, which is used as a very unique idea or concept now a days in corporate world to deliver a new leadership approach. The basic concept behind the idea is to generate the ownership at work place which plays a very important or a key role in the relationship with respect to the working place and working conditions (Mushin Lee \& Joon Koh, 2010). Empowering the employees is another way to create a strong relationship, to be decentralizing for an organization is a state of providing power to each main every employee, related to their field (Wang \& Clegg, 2011). The concept of empowering leadership is result positively in sharing knowledge and it also creates team to be effective and the relation is shown positive of empowering leaders' leads toward knowledge and to tan efficacy (Srivastava, Kathryn and Edwin, 2006).

1.3.3 Team leaders and their influence with responsibility sharing Team is a group of people who are working for a similar interest which take them to provide a similar result. The effectiveness of a team is due to the team leader who have the exact knowledge and information which is with him; the trust factor which helps to complete their task in an effective manner is the information and knowledge sharing within the team. This can accelerate the performance and the reputation of the team leader as well; the expertise and the willingness of the team will result positively because of the knowledge sharing (Lee, Gillespie, Mann \& Wearing, 2010). The behavior of the team members is impacted by the style of their team leader and as they learn from the team leader how to behave in an organization or a team, team leaders have their influence upon the whole team, is relationship of the behavior is proved to be positive. The followers have their own definition to define the team leader (Vondey, 2008).

\subsection{Objective and Statement of the Problem}

The organizational Culture, Norms and Success factors are largely defined, influenced and implemented by the Leadership of that organization. Theoretically the visionary and trustworthy leadership with strong determination with vision of the organization leads to successful milestone for that organization. However, there is large mix of theories suggesting the successful leadership styles including Charismatic and Contingent leadership styles. This study is designed to explore the most successful leadership style in organizations within the context of Pakistan. This study compares the Transformational Approach of leadership with Transactional Approach of Leaderships.

\subsection{Hypotheses of the Study}

H1: Transformational Leadership has significant positive effect on the organizational performance

$\mathrm{H} 2$ : Transactional Leadership has significant positive effect on the organizational performance

H3: Charismatic Action of Leadership has significant positive effect on the organizational 
performance

H4: Pay for performance act of Leadership has significant positive effect on the organizational performance

H5: Intellectual Stimulation act of Leadership has significant positive effect on the organizational performance

H6: Active Management by Exception act of Leadership has significant positive effect on the organizational performance

H7: Passive Management by Exception act of Leadership has significant positive effect on the organizational performance

H8: Inspiration Motivation act of Leadership has significant positive effect on the organizational performance

H9: Perform Rating based act of Leadership has significant positive effect on the organizational performance

H10: Individual Consideration act of Leadership has significant positive effect on the organizational performance

H11: Encouragement for High Morale act of Leadership has significant positive effect on the organizational performance

H12: Encouragement for Recognition act of Leadership has significant positive effect on the organizational performance

\section{Literature Review}

\subsection{Leadership Characteristics}

An individual at working place plays an important role to create the trust factor between the leaders and the subordinates. The relationship between the trust and the employees is positive; as the trust factor is greater the result of the organization outcome would be positive, it means that trust builds a strong relationship for leaders and their employees (Bernerth \& Walker, 2011). Leaders should develop their trust for the employees to look for the desired outcomes, as this trust can be increase by showing that they are a part of the organization, an organization which provides them the equal opportunities for them as for the leaders. Trust within the team is very much important, so that the team leader can disclose all the information and the knowledge he have with respect to the project and this will result in an effective manner. Trust between the team makes them to carry each other and produce the best optimum outcome out of the work (Lee, Gillespie, Mann \& Wearing, 2010).

\subsection{Leadership Styles}

A style of leadership which is use, to motivate, inspire and transform the follower into leaders that is called transformational style of leadership. It is inspires the works to work in a broaden interest of their own, make them innovate and creative. The psychological well-being of the employees is directly related to the well-being of the works as this style enhances the capability of the worker to understand their task in a better way. It also_give an idea to the leader about the capabilities of their follower and this help the leader to guide the follower (Nielsen, Randall, Yarker \& Brenner, 2008). Leader-Member Exchange (LMX Theory) is about how people carry a leadership position in a group through different means and exckange important information which create a strong relationship between the employees of the organization $(\&, 2011)$. Leader-member exchange is all about the relation between the leaders and their team, this theory have a very particle and theoretical application which is very useful but it 
Leadership style and Organizational Performance: A Comparative study between Transformational and Transactional Leadership styles

has some problems which are like the measurement of its effectiveness and its application (Schyns \& Blanc, 2011).

The top management plays a very vital role in an organization, as these executives carry the organization in a very diplomatic way by which the role of employees is not much significant but they have to make employees feel to be a part of their organization. For this reason the employees encourage the style in which they have the authority. Like, employees don't support a leadership style in which they think that their idea is not being taken seriously, they need a decentralize system in which their suggestion and their decisions are given the same importance and this creates motivational factor amongst the employees which gives a positive outcomes (Wang \& Clegg, 2011). According to a research the positive emotional climate is created only due to the facts of the organization, this result in a way if the condition of the organization is better and its is performing at its maximum level, generating revenue from sale and the revenue is continuously increasing, it is also measuring the growth of the organization in a very positive way, so trends to create a climate which is positive and the conflicts within the organization will obviously vanish due to the condition of the organization. This creates a positive emotional climate for the employees and make there working conditions more and more well (Ozcelik, Langton \& Aldrich, 2008).

The working of an organization is dependent upon three most important factors; trust, connectivity and thriving. It works like connectivity plays a role of an intermediately in the first half to develop the relationship between the trust and success, and then if you got or achieve the success mark then you would be getting connectivity and trust which will result in innovative ideas (Carmeli \& Spreitzer, 2009). Loyalty is the other factor for the promotion in the organizations, leader's role is important for giving the employees feedback about their performance and their tasks so that they can improve their performance. By doing this the employees get motivated and give positive response to the leaders in the form of the quality work (Breaugh, 2011).

Many companies do millions of attempt to get along with the fair service law, many of the firms have these problems between employees encouragement decision. Practical fairness is basically referring for dealing with equality and justness in building decision about the rewards and encouragement. Many of the past studies done to allocate on justice perception in promotion decisions in order that unfair treatment may have a negative impact for organization (Lemons \& Jones, 2001).

\subsection{Employee Perception about Leadership Styles}

Employee perceptions is considered to be the most important variable when it comes to measure the HR practices, as this is the major variable, which contributes a lot in the effectiveness of the organization. Implementation of any organization largely depends on the performance of its workforces. Notwithstanding of the size and depiction of an organization, the activity it commences, and the atmosphere in which it operates, its accomplishment depends on its employee's decisions and their behavior. It was witnessed that the effectual Leadership Styles has increase the performance of organization as well as their profits. Leadership Styles show a strong relationship with proficiency of firm (Nasurdin, Hemdi, 2008).

2.4 How do these Leadership Styles lead to employee satisfaction? Research influence of human resource practices on employee intention to quit state the technique to reduce employee turnover. The research suggests that using Leadership 
Styles lead to employee satisfaction, which reduces the employee turnover. Research also suggests human resource practice that includes compensation, training and development that will influence the level of job satisfaction of a new employee as well the old employee. (Michael Joseph Martine, 2010).

Human resource is a much-diversified field, which deals with many human resource problems, which include employee satisfaction, age group in organization, and length of service in entire organization. Whereas all these variable are directly proportion to employee perception. According to the whole research that we have conceived and after examining different articles and journal of different universities and publication we have derived an analysis on the basis of employee perception on HRD practices of an organization. After notifying that many researches regarding employee satisfaction, (Hunt \& Saul, 1975) state age and tenure had a positive and linear relationship with overall employee perception related to Job satisfaction. He also suggests that age have a strong association with contentment in male and vice versa in females. Human resource practices play a vital role in shaping employee attitude and employee perception. Employee has mindset and perspectives about many features of their jobs (Saari, Lise \& Timothy, 2004). From research and practice point of view employee attitude is largely based on job satisfaction. Job satisfaction maybe described as the positive experience or positive emotional state arising from an employee's current job. Of all the elements that lead to job satisfaction, satisfaction with the nature of the job is one of the main elements that result in job satisfaction. If an employee is pleased with his/her nature of the work and the task assigned, then they will be satisfied. Challenges in job, autonomy, variety and scope of work are the other elements that will also result in job satisfaction.

\subsection{Zeigarnik Effect and the leadership role}

Burke (2010) has mentioned in his article that research shows on Zeigarnik effect that people do remember those tasks which are unfinished more than those tasks which are finished. Different interfering things could be abolished by letting members to put together particular tactics for their particular unfinished tasks. Decrease of the interfering things was arbitrated by the seriousness of members' plans; those who in the end performed their tactics were those who also demonstrated no more interruption (Masicampo \& Baumeister, 2011).

People who have unfulfilled goals in their minds, it has been hypothesized those unfulfilled goals remain in mind until it has not been completed. It has been assumed that the interruption contributes a lot to the thinking process for achieving certain goals which are not achieved. The incomplete objectives always cause disruption in the mind for the duration of unrelated tasks which are being done, high rational ease of understanding to that particular goal related terms, and very unfortunate performance on the distinct tasks which are under process. It is argued that work-family conflict has an adverse effect on work satisfaction. But a leader's supportive leadership style, and an effective mentoring and training programs might reduce work-family conflict and in turn increase the job satisfaction of employees.

\section{Research Methods}


Leadership style and Organizational Performance: A Comparative study between Transformational and Transactional Leadership styles

\subsection{Method of Data Collection}

The Primary source for Data collection has been applied including comprehensive Survey and Direct Interview has been conducted from the relevant sample. This study is based on Primary source of Information by mean of Personal Interview and Survey from the relevant Population. The Relevant Population for this study includes the Corporate Professionals such as Leaders, Directors and Executives from more than 100 companies. However, the secondary source of Information shall be also be availed such as Survey Reports, Theoretical Frameworks etc.

\subsection{Sampling Technique}

The study proposes convenience based sampling; which is non-probability sampling technique where respondents are selected upon the convenience of the researcher. The Sampling procedure has no quotas imposed and the data collected from the population which was easily available and accessible to the researcher.

\subsection{Sample Size}

The universe for this is all Employees in working in corporate sector, the population is considered as all employees working in Pakistani Corporate sector. Out of the target population a sample of 800 respondents has been interviewed to collect the required information. The sample includes employees at tactical and operational management in corporate sector. The employees were encouraged to fill in their response in the questionnaire.

\subsection{Instrument of Data Collection}

Close ended Questionnaire and Likert Scale based questionnaire was used as an Instrument in this study, to know the impact of mentioned independent variables on employee's organizational commitment. The questioner is close ended with 5 five options i.e. Strongly Disagree, Disagree, Neutral, Agree and Strongly Disagree. Each option is assigned a coded value which shall be calculated in the one sample test. A well-prepared questionnaire has been designed which has been provided to the responded that fills this questionnaire and return it back. The questioner is close ended with 5 five options i.e. Strongly Disagree, Disagree, Neutral, Agree and Strongly Disagree. Each option is assigned a coded value which shall be calculated in the one sample test. The number starts from strongly disagree, which has been given value: 1 then value 2 is given to disagree, 3 for Neutral, 4 for agree and 5 for strongly agree.

\subsection{Conceptual Framework Development}

Based various theories and available literature, this study has been designed on the comparative analysis between Transformational and Transactional styles of leadership. We confine the characteristics of Transformational leaderships as: and that of Transactional leaderships as:

Dependent Variable: Organizational Success -Allen \& Meyer (1990) Independent Variable:
1. Charismatic Action of Leadership
2. Intellectual Stimulation act of Leadership
3. Inspiration Motivation act of Leadership
4. Individual Consideration act of Leadership
5. Encouragement for High Morale
6. Pay for performance act of Leadership
7. Active Management by Exception act of Leadership
8. Passive Management by Exception act of Leadership 
9. Performance Rating based act of Leadership

10. Encouragement for Recognition act of Leadership

3.5.1 Conceptual Framework designed

\section{Graph 3.5 Research Model Frameworks}

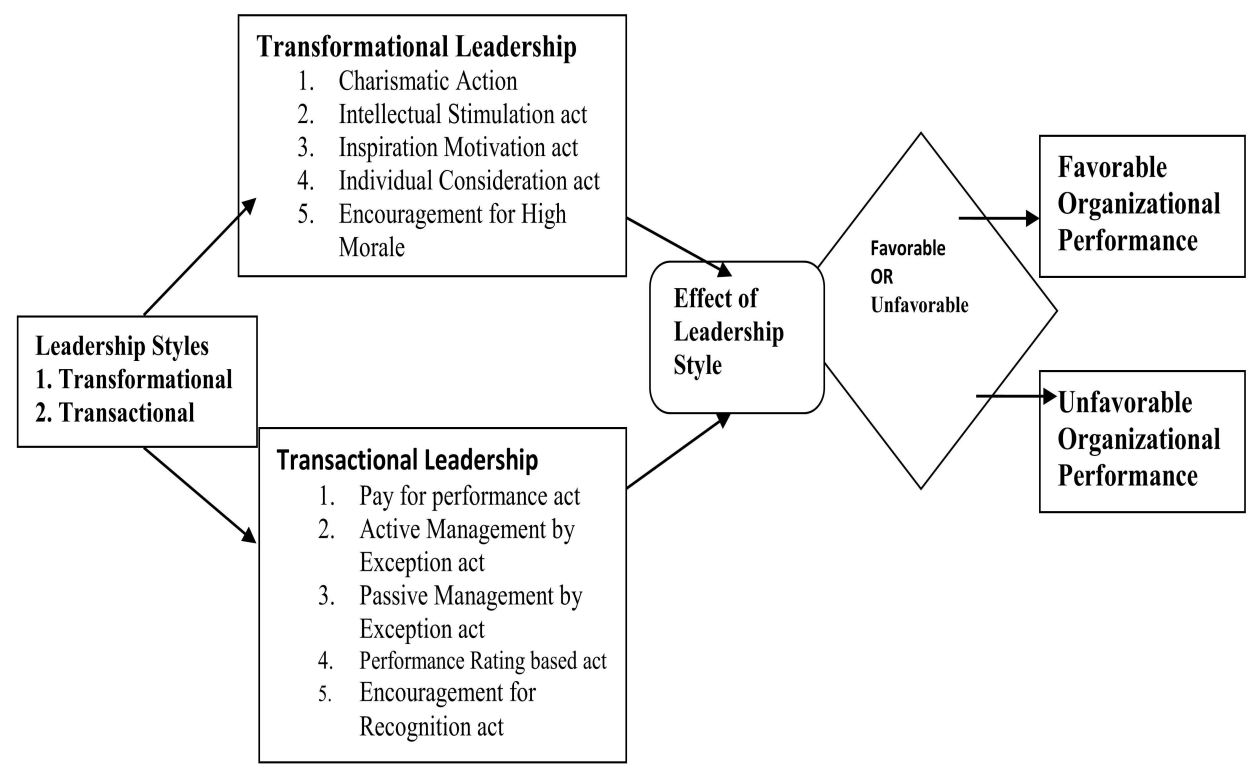

Source: The Model Framework Designed by Researcher

\subsection{Statistical Technique}

\subsubsection{Factor Analysis}

In the first part of our questionnaire, the respondents were asked about type of leadership in their respective organizations. In order to maintain the impartiality and fairness the Respondents were not directly asked about the type's leadership. They were asked to tick the suitable option about the various characteristics of the leadership such as: charismatic action, Performance rating, Pay for performance of Management by exception.

In order to make the comprehensive and empirical reliable concept of Transformational Leadership and the Transactional leadership the Factor analysis has been made on the first part of questionnaire. We have taken only two factors i.e. Transformational and Transactional and the relevant ten characteristics of the leadership. The factor analysis is a data dimension reduction technique; it shall categorically compress the various leadership characteristics into two Factors or the leadership types. 3.6.2 Regression Estimation on Two Factors

Based on the results of Factor Analysis, the various characteristics of leaderships are 
Leadership style and Organizational Performance: A Comparative study between Transformational and Transactional Leadership styles

divided on the two broad types of Leadership i.e. Transformational and Transactional Leadership. Finally, we selected 4 characteristics for each. The factor value of each Leadership have been created and saved. On the basis of that value, now we estimate the effect of Each Leadership on the organizational Performance. Basic function as already discussed:

\section{Model-1 1 Regression Estimation on Two Factors}

Organizational Performance $=\mathrm{f}($ Leadership type Transformational, Transactional $)$

$$
\text { OrgPerformance }=\alpha+\beta_{1} \text { TransfLeader }+\beta \text { TrasiLeader }+\vartheta
$$

Here

Org Performance

TransfLeader

TransiLeader
Organizational Performance

Transformational Leadership

Transactional Leadership

\subsubsection{Regression Estimation on Multi Factors}

Model-2 estimation (all Leadership characteristics estimation) Organizational performance $=\mathrm{f}(\mathrm{P}, \mathrm{IS}, \mathrm{AMBE}, \mathrm{CA}, \mathrm{PR}, \mathrm{IC}, \mathrm{IM}, \mathrm{Rec}, \mathrm{PMBE}, \mathrm{HM})$ Here:

P: $\quad$ Pay for performance

IS: Intellectual Stimulation

AMBE: Active Management by Exception

CA: Charismatic Action

PR: Perform Rating

IC: Individual Consideration

IM: Inspiration Motivation

Rec: Recognition

PMBE: Passive Management by Exception

HM: High Morale

\section{Statistical and Empirical Analysis}

\subsection{Results of the Statistical and Empirical Analysis}

4.1.1 Reliability of the Data

The value of Cronbach's Alpha (0.796) is greater than 0.5 that suggests that Categorical Data used is Reliable for Linear Regression Analysis. On the basis of Reliability test, now the Regression analysis may be made to investigate the effect of Leadership styles on the organizational Performance (see appendix)

\subsubsection{Factor Analysis}

In the first part of our questionnaire, the respondents were asked about type of leadership in their respective organizations. In order to maintain the impartiality and fairness the Respondents were not directly asked about the type's leadership. They were asked to tick the suitable option about the various characteristics of the leadership such as: charismatic action, Performance rating, Pay for performance of Management by exception.

In order to make the comprehensive and empirical reliable concept of Transformational 
Leadership and the Transactional leadership the Factor analysis has been made on the first part of questionnaire. We have taken only two factors i.e. Transformational and Transactional and the relevant ten characteristics of the leadership. The factor analysis is a data dimension reduction technique; it shall categorically compress the various leadership characteristics into two Factors or the leadership types. The results show that Charismatic type is explained in Transformational style with 91.5\%, whereas, the Pay for Performance is explained in Transactional style with 97.7\%. Likewise, the Intellectual simulation type is explained in Transformational style with 91.3\%, whereas, the AM by Exception is explained in Transactional style with 82.8\%. Similarly, the inspiration motivation type is explained in Transformational style with 81.1\%\%, whereas, the PM by Exception is explained in Transactional style with 96.8\%. Besides to it, the individual consideration type is explained in Transformational style with $81 \%$, whereas, the performance rating is explained in Transactional style with $89.8 \%$. On the other side the high morale and the act of recognition have insignificant correlation with each leadership style. The results can be summarized in table 4.4 (see appendix)

\subsubsection{Regression Estimation on Two Factors}

Based on the results of Factor Analysis, the various characteristics of leaderships are divided on the two broad types of Leadership i.e. Transformational and Transactional Leadership. Finally, we selected 4 characteristics for each. The factor value of each Leadership have been created and saved. On the basis of that value, now we estimate the effect of Each Leadership on the organizational Performance. Basic function as already discussed:

Organizational Performance $=\mathrm{f}($ Leadership type; Transformational, Transactional $)$

$$
\text { OrgPerformance }=\alpha+\beta_{1} \text { TransfLeader }+\beta \text { TrasiLeader }+\vartheta
$$

Here

Org Performance

TransfLeader

TrasiLeader

Organizational Performance

Transformational Leadership

Transactional Leadership

Based on the above Model, we apply OLS estimation; the results of the OLS estimation are depicted in table 4.18 to 4.20 .

Table 4.5 shows the Model summary, which explains that how much the model explains the results. The value of Adjusted R Square is 0.848 which means the model explains the cause up to $84.8 \%$, which means the Model applied here is reliable. Table 4.6 shows the results of the ANOVA related the selected Model. The value of sig is less than 0.05, which means the applied model is significant. Based on the results of Table 4.18 and 4.6, we can proceed for the estimation based on our model. The results of table 4.7 show the coefficients of the Model which is as:

By putting the estimated values the model becomes:

The results of model shows the both the types of leadership has significant effect on the organizational performance, however, the Transformational Leadership has significant 
Leadership style and Organizational Performance: A Comparative study between Transformational and Transactional Leadership styles

positive effect on the organizational performance, whereas the Transactional leadership has significant negative effect on the organizational performance. We can conclude that our first hypothesis is accepted which is that Transformational Leadership is significant positive, but the second hypothesis cannot be accepted because as per our estimation, the Transactional leadership has significant negative effect on organizational performance.

Since the sig value for the beta of transformational leadership is significant (sig value is less than 0.05) and the sign of beta is also positive, it means the transformational Leadership has significant positive effect on the organizational performance. Hence the $\mathrm{H} 1$ is accepted.

Likewise, the sig value for the beta of transformational leadership is significant (sig value is less than 0.05 ) but the sign of beta is negative, it means the Transactional Leadership has significant negative effect on the organizational performance. Hence the $\mathrm{H} 2$ cannot be accepted.

\subsubsection{Regression Estimation on Multi Factors}

Broader Explanation based on all characteristics estimation

In the first model we estimated the organizational performance based on various leadership characteristics. The objective of testing the effect of each individual leadership characteristics is to cross the results of Factor Analysis and the First Model. The Factor analysis reduced and compressed the leadership characteristics on Two Leadership types i.e. Transformational and Transactional leadership. Whereas our First model estimates effect of each type of leadership on the organizational characteristics and the estimation results concluded that transformational leadership has positive effect on the organizational performance, whereas the Transactional leadership has negative effect on the organizational performance. The second Model will cross check in such a way that whether the characteristics of Transformational Leadership as determined by the Factor analysis are in confirmation with the results of first model which concluded that Transformational leadership has significant positive effect on the organizational performance.

Model-2 estimation (all Leadership characteristics estimation)

Organizational performance $=\mathrm{f}(\mathrm{P}, \mathrm{IS}, \mathrm{AMBE}, \mathrm{CA}, \mathrm{PR}, \mathrm{IC}, \mathrm{IM}, \mathrm{Rec}, \mathrm{PMBE}, \mathrm{HM})$

$$
\operatorname{OrgPerf}=\alpha+\beta_{1} P+\beta_{2} I S+\beta_{3} A M B E+\beta_{4} C A+\beta_{5} P R+\beta_{6} I C+\beta_{7} I M+\beta_{8} \operatorname{Re} c+\beta_{9} P M B E+\beta_{10} H M+\vartheta
$$

Here:

P: $\quad$ Pay for performance

IS: Intellectual Stimulation

AMBE: Active Management by Exception

CA: Charismatic Action

PR: Perform Rating

IC: Individual Consideration

IM: Inspiration Motivation

Rec: Recognition

PMBE:Passive Management by Exception

HM: High Morale 
Model 2 (all Leadership characteristics estimation) can be derived as follows: f (P, IS, AMBE, CA, PR, IC, IM, Rec, PMBE, HM)

Based on the above Model, we apply OLS estimation; the results of the OLS estimation are depicted in table 4.8 to 4.10 .

Table 4.8 shows the Model summary for model 2, which explains that how much the model explains the results. The value of Adjusted R Square is 0.805 which means the model explains the cause up to $80.5 \%$, which means the Model applied here is reliable.

Table 4.9 shows the results of the ANOVA related the selected Model. The value of sig is less than 0.05, which means the applied model is significant. Based on the results of Table 4.8 and 4.9 and 4.21, (see appendix) we can proceed for the estimation based on our model.

The results of table 4.10 show the coefficients of the Model which is as: Model 2 (all Leadership characteristics estimation) can be derived as follows: f (P, IS, AMBE, CA, PR, IC, IM, Rec, PMBE, HM)

Table 4.23 shows the OLS estimation of Model 2, which shows the effect of each individual characteristics of leadership style on the organizational performance. The coefficients of all the variables are significant except to the three factors because which are: Recognition, Passive Management by Action and High Morale. The Model 2 may be estimated as follows:

The result of model 2 depicts the effect of each individual characteristics of leadership style on the organizational performance. The coefficients of all the variables are significant except to the three factors because which are: Recognition, Passive Management by.

The sig value for the beta of Charismatic Action of Leadership is significant (sig value is less than 0.05) and the sign of beta is also positive, it means the Charismatic Action of Leadership has significant positive effect on the organizational performance. Hence the third hypothesis is accepted.

The sig value for the beta of pay for performance characteristics is significant (sig value is less than 0.05) but the sign of beta is negative, this shows that the pay for performance characteristics of Leadership has significant negative effect on the organizational performance. The results are interesting, it means in long term the productivity of employees shall be negative if the performance is linked with Pay or the variable pay is offered to the employees. Hence the fourth hypothesis is accepted. Interestingly the effect of Active Management by Exception are appeared as very significant and positive as shown in table 4.10, whereas, the effect of Passive Management by Exception appeared as very insignificant, it means it does not affect the organizational performance. These results show the acceptance for sixth hypothesis and the rejection of seventh hypothesis. Besides to it, the results of the OLS estimations as depicted in table 4.10 shows that Inspiration Motivation act of Leadership has significant but negative effect on the organizational performance because the its sig value is less than 0.05 , but the beta coefficient is negative. It means individual consideration to the 
Leadership style and Organizational Performance: A Comparative study between Transformational and Transactional Leadership styles.

employees creates negative effect on the overall performance level. The intellectual simulation characteristics of the leadership have significant and positive effect on the performance of organization.

Table 4.10 further, shows that the Perform Rating based act of Leadership has significant negative effect on the organizational performance since its beta is significant but it is negative. It shows that it has negative effect on the organizational performance. The effect of Encouragement for High Morale act of Leadership is insignificant, it means Encouragement for High Morale act of Leadership has insignificant effect on the organizational performance, likewise, Encouragement for Recognition act of Leadership also has insignificant beta coefficient, it means Encouragement for Recognition act of Leadership has insignificant effect on the organizational performance

\section{Discussion, Conclusion and Future Research and Policy Implication 5.1 Discussion}

This study has been conducted with an objective to explore the effect of Leadership types such as Transformational Leadership and Transactional Leadership on the Organizational Performance. In order to maintain the impartiality and fairness the Respondents were not directly asked about the type's leadership. The results of the study suggest that Transactional Leadership has very significant negative effect on the performance of organization, which means the more an organization is inclined towards Transactional Leadership the weaker the Organizational Performance is. On the other side, Transformational Leadership has significant Positive effect on the performance of organization, which means the more an organization is inclined towards Transformational Leadership, organization the stronger the Organizational Performance is.

Besides to the two factors Model, a comprehensive Regression analysis also has been made to estimate the effect of each individual Leadership characteristic on the organizational Characteristics. The results suggest that the Charismatic Action, Intellectual Stimulation, Inspiration Motivation, Encouragement for High Morale characteristics of Transformational Leadership has significant positive effect on the Organizational Performance. Whereas, the Individual Consideration act of Transformational Leadership does not has significant effect on the Organizational Performance. Finally, the Passive Management by Exception act of Leadership, Encouragement for Recognition act of Leadership does not have significant effect on organizational performance.

\subsection{Conclusion}

This study provides the conclusion based on the Empirical findings, the statistical analysis includes: Factor analysis which has been used determine the key characteristics of each type of leadership, thereafter the OLS estimation has been applied to test the hypotheses of the study. The study concludes that the Charismatic Action, Intellectual Stimulation, Inspiration Motivation, Encouragement for High Morale characteristics of Transformational Leadership has significant positive effect on the Organizational Performance. In regard of the Transformational Leadership the further concludes that the Individual Consideration act of Transformational Leadership does not has significant effect on the Organizational Performance.

The study concludes about the Transactional Leadership that the Pay for performance and Performance Rating based act of Transactional Leadership has significant negative 
effect on the Organizational Performance. Interestingly, the Active Management by Exception act of Transactional Leadership has significant positive effect on the Organizational Performance.

Finally, the study concludes that the Passive Management by Exception act of Leadership, Encouragement for Recognition act of Leadership does not have significant effect on organizational performance.

\subsection{Future Research}

This study is based on survey results of 100 companies in Pakistan; it has been recommended for future research that it may be conducted on at least region wise such as South Asia, Middle East or Europe etc. Moreover, Comparison is made between the types of leaderships, in future research two or more types such as dictatorial or contingent style leader may be added for comprehensive analysis.

\subsection{Policy Implication and Recommendations}

This study provides empirical evidences that the Transformational Leadership is the most effective leadership in organizational performance. The key success factors or characteristics for a transformational leadership are Charismatic Action, Intellectual Stimulation, Inspiration Motivation, and Encouragement for High Morale characteristics of Transformational Leadership. On the other side, the transactional leadership

\section{REFRENCES}

Amburgey, W.O (2005). An analysis of the relationship between job satisfaction, organizational culture, and perceived leadership characteristics. Dissertation Submitted to University of Central Florida.

Bass, B.M. and Avolio, B.J., (1994). Improving organizational effectiveness through transformational leadership. Thousand Oaks, CA: Sage.

Breaugh, James A. (2011). Modeling the leadership promotion process. Journal of Leadership Psychology, 26, 264-277.

Burke, W.W. (2011). A perspective on the field of organization development and change: The Zeigarnik effect. Journal of Applied Behavioral Science, 47, 143-167

George A, Marcoulides and Ronald H. Heck. (1993). Organizational Culture and Performance: Proposing and Testing a Model. Organization science. 4, 209225 .

Hakan Ozcelik, Nancy Langton,ÊHoward Aldrich (2008). Doing well and doing good: The relationship between leadership practices that facilitate a positive emotional climate and organizational performance, Journal of Leadership Psychology, 23(2), $186-203$.

Hunt, John W. \& Saul Peter N., (1975). The Relationship of Age, Tenure, and Job Satisfaction in Males and Females. The Academy of Management Journal. Vol. 18, No. 4, pp. 690-702.

Jeremy B. Bernerth, H. Jack Walker (2009). Propensity to Trust and the Impact on Social Exchange. An Empirical Investigation. Journal of Leadership \& Organizational Studies, 15(3), 217-226.

Karen Yuan Wang and Stewart Clegg (2007). Managing to Lead in Private Enterprises in China. Work Values, Demography and the Development of Trust Leadership, $\hat{E} 3(2), \hat{E} 149-172$.

Karina Nielsen, $\hat{E} R$ aymond Randall, $\hat{E} J o a n n a ~ Y a r k e r E \hat{E} \&$ Sten-Olof Brenner, (2008). The 
Leadership style and Organizational Performance: A Comparative study between Transformational and Transactional Leadership styles

effects of transformational leadership on followers' perceived work characteristics and psychological well-being: A longitudinal study, An International Journal of Work, Health \& Organizations 22(1) 16-32.

Lo, C. M, Ramayah, T., Min, W.H., \& Songan, P. (2010). The relationship between leadership styles and organizational commitment in Malaysia: role of leader-member exchange. Asia Pacific Business Review, 16, 79-103.

Martin, M. J. (2011). Influlence of Human Resource Practices on Employee Intention to Quit.

Nasurdin, hemdi. Etal. (2008). Does perceived organizational support mediate the relationship between human resources management practice and organizational commitment. Asian Academy of Management Journal, Vol. 13, No. 1, Page No. $15-36$.

Pascal Paillé, Pierre-Sébastien Fournier, Sophie Lamontagne, (2011) "Relationships between commitments to the organization, the superior and the colleagues, and the intention to leave among truckers". International Journal of Organizational Analysis, Vol. 19:2, $92-108$

Pauline Lee, Nicole Gillespie, Leon Mann, Alexander Wearing (2010). Leadership and trust: Their effect on knowledge sharing and team performance. Management Learning $\hat{E} 41(4), \hat{E} 473-491$.

Voon, M.L., Lo, M.C., Ngui, K.S., \& Ayob, N. B. (2010). The influence of leadership styles on employees' job satisfaction in public sector organizations in Malaysia.

International Journal of Business Management and Social Sciences, 2, 1, 24-32. Wim van Breukelen, Birgit Schyns, Pascale Le Blanc (2006). Leader-Member Exchange Theory and Research. Accomplishments and Future Challenges, leadership,Ê2(3), 295-316. 


\section{Appendix}

Table 4.1 Reliability Statistics

\begin{tabular}{|l|l|}
\hline & \\
\hline Cronbach's Alpha & N of Items \\
\hline .796 & 20 \\
\hline
\end{tabular}

Table 4.2 Total Variance Explained

\begin{tabular}{|c|c|c|c|c|c|c|c|c|c|}
\hline \multirow[b]{2}{*}{ Component } & \multicolumn{3}{|c|}{ Initial Eigenvalues } & \multicolumn{3}{|c|}{$\begin{array}{c}\text { Extraction Sums of Squared } \\
\text { Loadings }\end{array}$} & \multicolumn{3}{|c|}{ Rotation Sums of Squared Loadings } \\
\hline & Total & $\begin{array}{c}\% \text { of } \\
\text { Variance }\end{array}$ & $\begin{array}{c}\text { Cumulative } \\
\%\end{array}$ & Total & $\begin{array}{c}\% \text { of } \\
\text { Variance }\end{array}$ & $\begin{array}{c}\text { Cumulative } \\
\%\end{array}$ & Total & $\begin{array}{c}\% \text { of } \\
\text { Variance }\end{array}$ & $\begin{array}{c}\text { Cumulative } \\
\%\end{array}$ \\
\hline 1 & 4.099 & 40.993 & 40.993 & 4.099 & 40.993 & 40.993 & 3.583 & 35.831 & 35.831 \\
\hline 2 & 2.671 & 26.714 & 67.707 & 2.671 & 26.714 & 67.707 & 3.188 & 31.876 & 67.707 \\
\hline 3 & 1.381 & 13.807 & 81.514 & & & & & & \\
\hline 4 & .736 & 7.357 & 88.871 & & & & & & \\
\hline 5 & .560 & 5.595 & 94.466 & & & & & & \\
\hline 6 & .266 & 2.664 & 97.130 & & & & & & \\
\hline 7 & .137 & 1.368 & 98.499 & & & & & & \\
\hline 8 & .092 & .920 & 99.418 & & & & & & \\
\hline 9 & .043 & .430 & 99.848 & & & & & & \\
\hline 10 & .015 & .152 & 100.000 & & & & & & \\
\hline
\end{tabular}

Extraction Method: Principal Component Analysis.

\section{Table 4.3 Rotated Component MatrixTable 4.3 Rotated Component Matrix}

\begin{tabular}{|l|c|c|}
\hline \multirow{2}{*}{} & \multicolumn{2}{|c|}{ Component } \\
\cline { 2 - 3 } & 1 (Transactional Leadership) & 2 (Transformational Leadership) \\
\hline Charismatic Action & -.104 & .915 \\
Pay for performance & .977 & -.024 \\
Intellectual Stimulation & -.194 & .913 \\
AM by Exception & .828 & -.100 \\
PM by Exception & .968 & -.062 \\
Insp Motivation & .016 & .811 \\
Perform Rating & .899 & -.104 \\
Indv Consideration & -.160 & .911 \\
High Morale & .125 & -.029 \\
Recognition & .326 & -.055 \\
\hline
\end{tabular}

Extraction Method: Principal Component Analysis.

Rotation Method: Varimax with Kaiser Normalization.

a. Rotation converged in 3 iterations. 
Leadership style and Organizational Performance: A Comparative study between Transformational and

Transactional Leadership styles

Table 4.4

\begin{tabular}{|l|l|}
\hline Characteristics & Relating to the Type of Leadership \\
\hline Charismatic Action & Transformational \\
\hline Pay for performance & Transactional \\
\hline Intellectual Stimulation & Transformational \\
\hline Active Management by Exception & Transactional \\
\hline Passive Management by Exception & Transactional \\
\hline Inspiration Motivation & Transformational \\
\hline Perform Rating & Transactional \\
\hline Individual Consideration & Transformational \\
\hline High Morale & INSIGNIFICANT RESULT \\
\hline Recognition & INSIGNIFICANT RESULT \\
\hline
\end{tabular}

Table 4.5 Model Summary for Model-1

\begin{tabular}{|l|r|r|r|c|}
\hline Model & \multicolumn{1}{|c|}{$\mathrm{R}$} & R Square & \multicolumn{1}{c|}{$\begin{array}{c}\text { Adjusted R } \\
\text { Square }\end{array}$} & $\begin{array}{c}\text { Std. Error of the } \\
\text { Estimate }\end{array}$ \\
\hline 1 & $.921^{\mathrm{a}}$ & .848 & .848 & .35540 \\
\hline
\end{tabular}

a. Predictors: (Constant), REGR factor Transformational, REGR factor

Traditonal

Table 4.6 ANOVA for Model-1

\begin{tabular}{|ll|r|r|r|c|c|}
\hline \multicolumn{1}{|l|}{} & Sodel & Sum of Squares & df & Mean Square & F & Sig. \\
\hline 1 & Regression & 561.330 & 2 & 280.665 & 2222.003 & $.000^{\mathrm{a}}$ \\
& Residual & 100.670 & 797 & .126 & & \\
& Total & 662.000 & 799 & & & \\
\hline
\end{tabular}

a. Predictors: (Constant), REGR factor Transformational, REGR factor Transactional

Table 4.7 Coefficients for Model-1

\begin{tabular}{|c|c|c|c|c|c|c|}
\hline \multirow{2}{*}{\multicolumn{2}{|c|}{ Model }} & \multicolumn{2}{|c|}{$\begin{array}{l}\text { Unstandardized } \\
\text { Coefficients }\end{array}$} & \multirow{2}{*}{$\begin{array}{c}\text { Standardized } \\
\text { Coefficients }\end{array}$} & \multirow[b]{2}{*}{$\mathrm{t}$} & \multirow[b]{2}{*}{ Sig. } \\
\hline & & $\mathrm{B}$ & Std. Error & & & \\
\hline \multirow[t]{3}{*}{1} & (Constant) & 3.850 & .013 & & 306.397 & .000 \\
\hline & REGR factor Transactional & -.095 & .013 & -.104 & -7.528 & .000 \\
\hline & REGR factor Transformational & .833 & .013 & .915 & 66.237 & .000 \\
\hline
\end{tabular}

a. Dependent Variable: Organ_Performance

Table 4.8 Model Summary for Model-2

\begin{tabular}{|l|r|r|r|r|}
\hline Model & \multicolumn{1}{|c|}{$\mathrm{R}$} & R Square & $\begin{array}{c}\text { Adjusted R } \\
\text { Square }\end{array}$ & $\begin{array}{c}\text { Std. Error of the } \\
\text { Estimate }\end{array}$ \\
\hline 1 & $.901^{\mathrm{a}}$ & .812 & .805 & .39796 \\
\hline
\end{tabular}

Table 4.9 ANOVA for Model-2 
Table 4.9 ANOVA for Model-2

\begin{tabular}{|rl|r|r|r|r|r|}
\hline Model & & Sum of Squares & df & Mean Square & F & Sig. \\
\hline 1 & Regression & 203.273 & 11 & 18.479 & 116.683 & $.000^{a}$ \\
& Residual & 47.195 & 298 & .158 & & \\
Total & 250.468 & 309 & & & \\
\hline
\end{tabular}

Table 4.10 Coefficients for Model-2

\begin{tabular}{|c|c|c|c|c|c|c|}
\hline \multirow[b]{2}{*}{ Mode } & & \multicolumn{2}{|c|}{ Unstandardized Coefficients } & \multirow{2}{*}{$\begin{array}{c}\begin{array}{c}\text { Standardized } \\
\text { Coefficients }\end{array} \\
\text { Beta }\end{array}$} & \multirow[b]{2}{*}{$\mathrm{t}$} & \multirow[b]{2}{*}{ Sig. } \\
\hline & & B & Std. Error & & & \\
\hline \multirow[t]{11}{*}{1} & (Constant) & 3.159 & .271 & & 11.640 & .000 \\
\hline & Pay & -.286 & .101 & -.376 & -2.824 & .005 \\
\hline & IntellectualStimulation & .587 & .081 & .657 & 7.290 & .000 \\
\hline & ActMbyException & .102 & .041 & .131 & 2.499 & .013 \\
\hline & CharismaticAction & .495 & .097 & .657 & 5.109 & .000 \\
\hline & PerformRating & -.514 & .036 & -.552 & -14.111 & .000 \\
\hline & IndvConsideration & -.212 & .102 & -.204 & -2.087 & .038 \\
\hline & InspMotivation & .119 & .025 & .163 & 4.690 & .000 \\
\hline & Recognition & -.039 & .029 & -.048 & -1.344 & .180 \\
\hline & PasMbyException & .011 & .020 & .015 & .544 & .587 \\
\hline & HighMorale & .031 & .018 & .043 & 1.680 & .094 \\
\hline
\end{tabular}

a. Dependent Variable: Organ Performance 